\title{
Revelations on the Distant Online Education Development in China from the 2019 Novel Coronavirus
}

\author{
Zhihong $\mathrm{Li}^{1, *}$ \\ ${ }^{1}$ Business School, Jianghan University, Wuhan, Hubei 430056, China \\ *Corresponding author. Email: linanwudingbang@163.com
}

\begin{abstract}
The break-out of 2019 Novel Coronavirus at the start of 2020 makes the whole educational system in China enter into the hardest first half of that year. How did the distant online educational system help the student and teacher spend such a hard time in China? It is worthy to be discussed. Therefore, the paper first reviews the actual situation of the distant online educational system in China at that time, and then disentangles the challenges met with in the aspect of the online teaching and learning under the 2019 Novel Coronavirus and the relative solutions at that time. By way of analyzing numerous literature and comparative study, the paper finally sums up some revelations and concludes that the distant online educational system concerns the training of the skilled personnel and also the setting up of the online platform, etc. and that it should be kept up with the progress pace of the information and network technology.
\end{abstract}

Keywords: Revelations, Distant online education, 2019 Novel Coronavirus, China.

\section{INTRODUCTION}

At the start of 2020, the outburst of the 2019 Novel Coronavirus made all walks of life in China facing serious challenge. At that time, it was the time for the educational system to open school. The high aggregability \& mobility of the educational field is the favorite of the 2019 Novel Coronavirus as virulent infectious disease. The educational system suffered a more dilemma than ever before. It's a tough question to open or not to open for the educational department. To open school means speeding up the spread of the virus while not to open means delaying of the student to be educated. The former will make more people infected or lose life and the latter will cause over 200 million students to finish their study in China. At this moment, the Educational Department issued a Notification to Delay Opening School in the Spring Semester on January 27, 2020 and then put forward the proposal of "Stopping class but not stopping learning" by using the internet platform. A wide online education all over the country started.

\section{ACTUAL SITUATION OF THE ONLINE EDUCATION IN CHINA UNDER THE 2019 NOVEL CORONAVIRUS}

In the principle of preventing the epidemic virus from spreading in the school and safeguarding the health of students and faculty and staffs and also being unable to sacrifice the study of the student, the online study is the only feasible choice then. Owing to a fond foundation of the educational information system of the governmental project of the full coverage of the digital educational resources in the teaching \& learning point, the internet access rate of the primary and middle school in the whole nation rises from $25 \%$ to $98.4 \%$. The multimedia classroom gets to $92 \%$. The national public educational resource service system has been set up and 28 provincial platforms have been accessed inside. The national network learning space of over 100 million for the teacher \& student has been opened. 3 thousand national premium courses open online and 7 thousand national and 10 thousand online \& offline mixed premium courses have been opened. Besides, the information \& 
network level of the faculty \& staffs and managers in the school have been raised [1]. In the meantime, various on-line teaching platforms such as TENCENT MEETING, DINGDING, YUKETANG, etc. have successfully assured the realization of the distant education during the epidemic situation, of which several Apps like TENCENT MEETING and DINGDING have been introduced to the students all over the world. Take the YUKETANG for example, from Feb.14, 2020, it began to increase independent servers one after another in order to insure the stable operation of the teaching in the educational institutes. In the teaching content, it has uploaded brand new web page class, online test system and online exam paper making, issuing and supervising the exam, etc. In the class style, it newly increases lots of functions like multiple screen live, large screen learning and double-time playback, etc. During the epidemic period, the demand for the distant education has been rising so fast that it surpasses anytime in the past (see "Table 1").

Table 1. Demands of Some Distant Educational Platforms during the Epidemic

\begin{tabular}{|l|l|l|l|}
\hline \multicolumn{1}{|c|}{ Platforms } & \multicolumn{1}{|c|}{$\begin{array}{c}\text { New Users } \\
\text { (million) }\end{array}$} & \multicolumn{1}{c|}{$\begin{array}{c}\text { People per Month } \\
\text { (million) }\end{array}$} & \multicolumn{1}{c|}{$\begin{array}{c}\text { Educational } \\
\text { Institutes }\end{array}$} \\
\hline XUEXI TONG & 18 & 13.5 & Over 4000 \\
\hline YU KETANG & 26 & Over 30 & Over 6000 \\
\hline DINGDING & Over 300 & 130 & 140000 \\
\hline
\end{tabular}

In the higher educational institutes, besides the free online class like MOOC and virtual simulation teaching resources opened by the national educational department, CERNET has provided CARSI to share the global academic resources including 190 thousand journals, more than ten thousand experimental videos and so on from 34 main academic resources providers at home and abroad.

\section{CHALLENGES FACED BY THE DISTANT EDUCATION IN CHINA UNDER THE 2019 NOVEL CORONAVIRUS}

\subsection{Insufficient Insurance of the Teaching Quality}

For a long period of time, the instructors in China are quite familiar with the off-line class. The online class without any preparations makes most of them unable to adapt to the new teaching approach all at once, especially for those aged teachers. The main difficulties are embodied as following: first, unfamiliar with the teaching instruments or APP or relative software. For instance, some teachers spoke to the air for a whole class at one time and the students received no signals. Then, commonly in the off line class, teachers can judge whether the students have understood the key knowledge or not by their reaction in the class. But in the online class, due to the shortage of the interaction between the teacher and the student, teachers can't adjust their teaching process or style according to the students' reaction, which may affect the teaching result[2]. In particular, in the online class, teachers are unable to supervise if the students are listening to the class or not by the backstage data.

\subsection{Insufficiency of the Virtual Simulation Resources for the Class of Experiment}

The online teaching makes the practical class facing a big obstacle. Either the labs of the general higher educational institutes or the vocational Colleges have to do the practical work with the aid of the virtual simulation system in the whole course of the epidemic period. As long as the network exists, the student can enter the virtual system or lab to learn by way of portable phones, iPad or computers because the student can't return to school at that time in China. Through this epidemic, the higher educational institutes in China realize the shortage of the virtual simulation resources and importance to set up the virtual simulation lab, especially for the vocational colleges.

\subsection{Difference of the Student's Self-control May Enlarge the Polarization of the Learning Result}

Distant education has its advantages and also disadvantages. Its advantages are reflected in the aspect of a higher concern between the teacher and 
the student. The teacher uses the live class or QQ or Wechat, etc. to communicate with the student such as online discussion and ask $\&$ answer the question, which lets the teacher and the student more close than in the off line class. Even those students who are unwilling to interact with others in nature may be of enthusiasm to join in the interaction on the line. Moreover, during the period of the unusual event like the epidemic situation, the distant education has its remarkable contribution to the people's study. Naturally, the distant education has its shortcomings due to the shortage of the face-toface supervision. The learning result for all the learners can't be well kept. As for the students who can well control themselves in the online class, they may obtain a good learning result. But for those that lack self-control ability, they are easily distracted or absent minded in the online class and then their learning result may be quite bad. All these will lead to a situation: polarization of the students' achievement in the online learning.

\subsection{Imbalance of the Network Infrastructure}

The internet installation is the base of the distant education. For a long period, although the urbanization has much changed the formation of the urban and the rural population (see the following
"Figure 1"), the delayed economic development level restrains the input into the construction of the network installations. The network infrastructure in China has been developed between the vast countryside and the city in an imbalanced way. Although the coverage rate of the network like the base station and $4 \mathrm{G}$ has been improved in the countryside in recent years, the remote rural or mountain area is still neglected. Also, the network quality of the rural area covered by the network has much room to be improved. Take it for example, during this epidemic period when large quantity of people surf the internet, lots of troubles like slow speed and internet congestion or even connection broken, etc. occurred. Therefore, in order to solve these problems universally existing whether in the countryside or in the city, it is quite necessary to set up the special network for the distant education, especially for the countryside and the remote area. For instance, at the beginning of the 2019 Novel Coronavirus, when all the students quarantined at home both in the primary \& middle school and the higher educational institute in the whole country had class synchronously on the line by way of live teaching, the users on the TENCENT platform reached 400 millions and the online communication was often down or inaccessible, which greatly hindered the normal implementation of the teaching at that time.

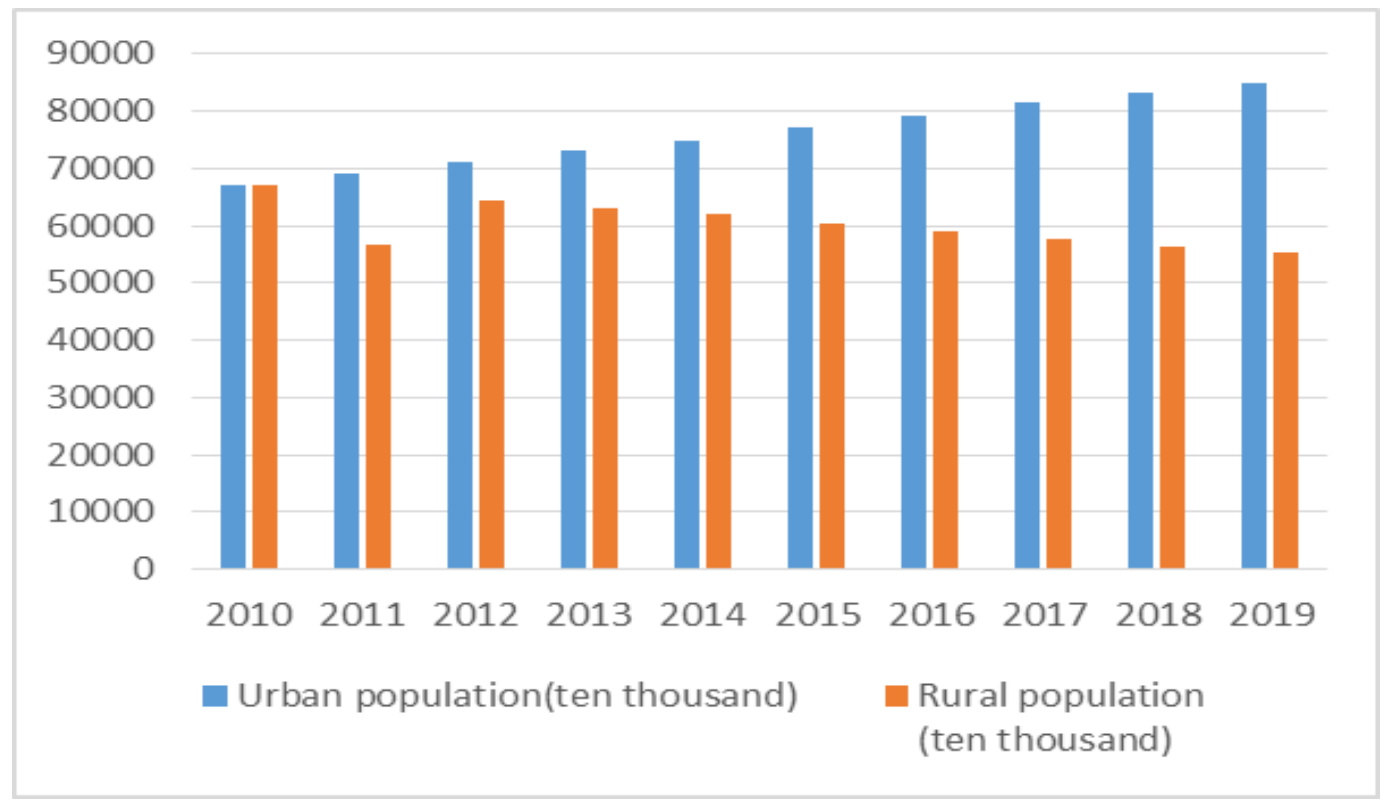

Figure 1 Changes of the Population between the Urban and the Rural Areas in Recent Years[3]. 


\section{REVELATIONS TO THE DISTANT EDUCATION DEVELOPMENT IN CHINA FROM THE 2019 NOVEL CORONAVIRUS}

\subsection{Implementation and Sharing Conjointly by Region of the Total Coverage of the Network Infrastructure Both in the Urban and in the Rural Area}

The network infrastructure is the carrier to further develop the distant education. Considering that the vast national surface, of which the rural area surpasses $60 \%$ by the end of 2019 and the massive population, of which the rural people occupy about $40 \%$ [4], it's a very hard task to accomplish the aim of total coverage of the installation all at once. We can build it step by step in order according to the administrative division. At the same time, the relative regional government ought to make an overall plan to comprehensively use the public place, buildings and installations or else to support the layout of $5 \mathrm{G}$ base station. The practice of some regions in the construction of $5 \mathrm{G}$ base station has proved this approach is feasible in China. For instance, by the end of 2019 in which $5 \mathrm{G}$ was just started, 1257 base stations in $5 \mathrm{G}$ had been set up in the western new area of Qingdao province, occupying $18.49 \%$ of the total yearly quantity in $5 \mathrm{G}$ there; 44 commercial pilot projects had been engaged in for the aim of industrial enabling, industrial intelligence and industrial competent congregation by the communication companies of Telecom, Unicom and Mobile[5]. Also, according to the statistic data done by the Telecom, Unicom and Mobile, the internet communication infrastructure had got to a total coverage of the internet communication in all 1663 communities of the whole city in Kunming by 2019. Moreover, in all its distant poor villages, the target to the total coverage of the internet communication had been reached by $100 \%$, reported by Poverty Alleviation Office of the city [6]. By September 2020, a total coverage of the internet in $5 \mathrm{G}$ had been accomplished in 16 urban areas and all the main cities of 137 counties in Shandong Province [7].

\subsection{Further Enrichment of the Professional Distant Educational Resource Platforms}

Before the outbreak of the 2019 Novel Coronavirus, in the background of integrating the information and education, the educational department pushed the concerned informational office of the school to have started the reform of the teaching mode such as MOOC, SPOC and micro class, etc., which had left deep impression on some teachers and students. However, in spite of these achievements, that the sudden epidemic forced all the teaching to be deployed for the isolated people still made the online teaching in strained circumstances in the aspect of the teaching resources. After all, at that time, the distant teaching this time concerned several 100 thousand schools, 280 million students and 17 million instructors. All of them were obliged to have class online synchronously! Coordinated unitedly by the Educational Department in China, the network service assurance like cloud service, network bandwidth and so forth was kept by CERNET and Telecom, Unicom and Mobile. But, the professional online teaching resources such as courseware for different disciplines, assignments and tests, etc. were in much shortage [8]. So, in order to better adapt to the requirements of the distant teaching especially in the period of abnormal conditions, a stable, fast and secure educational proper network must be established as soon as possible since the epidemic is still widespread in the whole world.

\subsection{Tempering of the Instructor with Multiple Competences}

Traditionally, most teachers have been familiar with off-line teaching. However, it is a great challenge for the teacher to turn into the online teaching in a short period, especially for those who are elder. In one hand, they are unfamiliar with the hardware and software and various kinds of Apps in the internet; on the other hand, a successful online class concerns the changes not only in the teaching style but also the teaching content. As a teacher, he or she must change the teaching approach quite skilled by him or herself and redesign the courseware according to the online rules so as to achieve the interaction effect. At the same time, the teaching content and assignments for the distant education ought to adapt to the student's requirements, which are neither too difficult nor too rigid. Besides, during the offline teaching, the instructor can face real students while 
he has to talk to a screen in the online class, which needs any other ability of the teacher just like an actor so as to animate the class atmosphere. That's to say, to carry out the online class successfully, a teacher must hold the competency of discipline, interesting linguistic expression, internet thinking, information technology and the application of all kinds of Apps, etc. To sum up, the fast evolution of the internet has provided us the so many opportunities for the distant education at the current moment that it is the time to re-engineer the educational system. This epidemic has been speeding up the reform of the education. The teacher, as one main party of the education, must actively change himself or herself in the aspects of ideology, concepts, knowledge and ability structure, skills and conducts and so on for the purpose of being suitable for the new educational conditions. Otherwise, the risk to be knocked out will occur.

\subsection{Training in the Awareness and Ability of the Student's Self-discipline}

During the offline class, many rules and regulations in the school restrain the student from being absent for class, self study and work \& rest, etc. However, the distant education is often finished without any restrains or supervision to the student. If a student is not strict with himself or herself in the class, he or she may get nothing for the study. Generally speaking, the self-discipline ability for the students of the middle \& primary school is weak while the students in the higher educational institutes have better self-discipline ability, because the students in the college or university, as being grown up, usually have stronger self-control ability to resist various kinds of temptation and also the online teaching has the advantages over the offline teaching, for instance, in the online class, the student can flexibly plan his or her time and listen to class at the time most suitable for his or her habit. Even so, some university students are still lack of the self-control ability, which makes each higher educational institute formulates lots of rules or regulations. The students in the middle \& primary school, as minors, are often unable to control themselves in the class because they have been familiar with studying under the strict discipline. After all, learning is not an easy thing and let alone to learn by themselves for most of them. So, it is quite necessary and important to keep training the awareness \& ability of the students' self-discipline whether they are the students from the middle \& primary school or from the college/ university.

\subsection{Obligation of the Coordination from the Multiple Parties for the Online Teaching and Learning}

The separation in the space between the instructor and the student is the remarkable feature. The whole online education relates to schools, families, enterprises and governments, etc. First, the educational management service, teachers are the obliged elements; then the student \& families[9] have the same importance as the teacher \& school administrators; next, internet infrastructure need the enterprise to set up and maintain; besides, the online platform such as software, Apps, and learning materials, etc. requires the professional organization to develop and moreover, all these parties demand the authorities or concerned governments to coordinate so as to maximize the efficiency and effectiveness of the online educational system. In another word, the whole online educational system is just like an orchestra. The educational department is the conductor; instructors and students are the band players; the administrators from the schools and the family members are the bandstands; the people from the enterprise are the instrument makers and those from the professional online platform are the instrument tuners. Any vacancy of these stakeholders will lead to an incongruity of the whole orchestra and it is impossible to play a beautiful symphonic music. Therefore, the online education is large systematic engineer and needs the conjoint efforts of all walks of life in the whole society in order to obtain an ideal effect.

\subsection{Further Improvement of the Cloud Educational System}

The online education on a large scale originated from the 2019 Novel Coronavirus has made thorough test to the distant educational resources set up in China and also accumulation of more extensive educational resources. The existent online educational infrastructure [10] together with the rapid strides of $5 \mathrm{G}$ has contributed much to the development of the distant education. In 2020, cloud school opening, cloud class, cloud test, cloud dissertation defense, cloud graduation and cloud recruitment and so on have played a role that can't be replaced for the normal operation of the educational system. However, some insufficiency still exists in the cloud resources of the online 
educational system. In order to insure better teaching \& learning results, besides the infrastructure like internet, platforms, instructors \& students, abundant educational resources should be uploaded into the cloud successively. In this way, the resources in the cloud will meet the diversified needs for the people's learning and teaching. It is a good example for the construction of the cloud resources system in the first half of 2010 in China. At that time, anti-epidemic is the most important task, but teaching \& learning for the school can't be absolutely neglected. Thus, the online class began. To enrich the existed cloud educational resources, quite a lot of higher educational institutes such as Tsinghua University, Beijing Foreign Studies University, etc. have offered the free online teaching \& learning resources; The National Opening University has provided the knowledge service about scientific anti-epidemic, etc. for the whole society. In the meantime, with the more and more serious epidemic situation in the whole world, the higher educational institutes in China have opened the international online educational class in the English version so as to share the China's online teaching \& learning experience. Although the cloud resources system has been advanced much, to satisfy the various changing demands of the people in the whole world, it has a long, long way to go.

\section{CONCLUSION}

In the times of the fast evolution of the internet, the distant education, as an important part of the educational system, has been showing its obliged existence. The educational institute must keep pace with the times and make full use of it to serve the teaching \& learning aim. Only in this way can the educational institute cultivate the person able to cater for the demand of the society.

\section{AUTHORS' CONTRIBUTIONS}

This paper is independently completed by Zhihong Li.

\section{ACKNOWLEDGMENTS}

The paper is funded by the Discipline Group of the Integrative Management Between Economy and Industry in the City Circle, by the Wuhan Studies Institute, Hubei, China (IWHS20172001), and by Research Center on the Development of the Manufacturing Industry of the Wuhan City Circle, China (wz201607).

\section{REFERENCES}

[1] https://baike.baidu.com/item/\%E4\%BA\%A7\% E4\%B8\%9A\%E9\%93\%BE/8725235?fr=aladd in.

[2] Yanping Liu, Hongtao Guan, Lixia Wang. Countermeasures to the Epidemic by the University and Challenges Faced, Decisions and Exploration, No.8, 2020. http://www.fx361.com/page/2020/0511/66422 07.shtml.

[3] https://new.qq.com/rain/a/20200414a0uhz900.

[4] https://zujuan.xkw.com/10q10115983.htmly.

[5] https://baijiahao.baidu.com/s?id=1662102529 $612087867 \& \mathrm{wfr}=$ spider $\&$ for $=\mathrm{pc}$

[6] https://baijiahao.baidu.com/s?id=1674070000 $970452486 \&$ wfr=spider $\&$ for $=$ pc.

[7] https://baijiahao.baidu.com/s?id=1678979091 $440015374 \& w f r=$ spider $\&$ for $=$ pcy.

[8] How to Deal with the Challenges Brought by the Epidemic in Managing the Education? http://www.jyb.cn/rmtzgjyb/202005/t2020052 7_331245.html.

[9] Changyu Shao. Six Challenges Faced by the Family Education under the Epidemic, Educational Newspaper of Shandong. Edition 1, May 27, 2020.

[10] Yingying Dong, Xingyuan Shao. Exploration of the Online Educational Mode in the Conditions of the Internet Plus. Comparative Research of the Cultural Innovation, 2019(29). 